\title{
Predicting the probability of falls in community-dwelling elderly individuals using the trail-walking test
}

\author{
Minoru Yamada $\cdot$ Noriaki Ichihashi
}

Received: 9 March 2010/Accepted: 27 April 2010/Published online: 25 May 2010

(c) The Japanese Society for Hygiene 2010

\begin{abstract}
Background Falling is a common problem in the fastgrowing elderly population. Multitasking or engaging in two or more activities at the same time is common in daily living.

Objective To determine the usefulness of the trailwalking test (TWT) for predicting a fall in communitydwelling elderly individuals.

Methods This was a prospective study in which the TWT was used to evaluate the risk of falling among a group of community-dwelling elderly individuals $(n=171)$ with a mean age of $80.5 \pm 5.6$ years. The following tests were conducted: TWT, trail-making test (TMT), timed-upand-go test (TUG), functional reach (FR) test, one-leg standing (OLS) test, and 10-m walking time test. Testretest reliability was assessed by repeating the TWT within 2 weeks of the first trial, and there was a 1-year follow-up. Stepwise logistic regression analysis was used to analyze whether the TWT, TMT, TUG, FR, OLS, or 10-m walking tests predicted falling.

Results The test-retest reliability of TWT was high (intraclass correlation coefficient $0.945, p<0.001$ ). Fiftynine participants $(34.5 \%)$ had reported a fall during the year preceding the 1-year follow-up. The stepwise logistic regression analysis revealed that only the TWT was significantly related to falling (odds ratio $1.160,95 \%$ confidence interval $1.107-1.214 ; p<0.001$ ). In total, $77.8 \%$ of cases were correctly classified.
\end{abstract}

M. Yamada $(\square) \cdot$ N. Ichihashi

Department of Human Health Sciences, Kyoto University

Graduate School of Medicine, 53 Kawahara-cho Shogoin,

Sakyo-ku, Kyoto, Kyoto 606-8507, Japan

e-mail: yamada@hs.med.kyoto-u.ac.jp
Conclusion When reliability and validity were considered, the TWT was most useful test of those evaluated for assessing the risk of fall among our elderly cohort.

Keywords Fall · Elderly · Trail-walking test ·

Predictor $\cdot$ Complex-task condition

\section{Introduction}

It has been estimated that $32 \%$ of community-dwelling elderly individuals aged $\geq 75$ years will fall at least once during a 1-year interval and that $24 \%$ of these individuals will sustain serious injuries $[1,2]$. The medical costs related to falls are substantial, with fall-related injuries in individuals aged $\geq 60$ years costing more than UK 981 million pounds per year [3]. Falling is therefore a common problem in the growing elderly population.

Previous reports have identified a myriad of risk factors associated with falls among the elderly, including agerelated changes to gait pattern [4], deficits in the musculoskeletal system [5], proprioception [6], and vestibular system, all of which will have a detrimental effect on locomotion. Most falls occur during locomotion and therefore, unsurprisingly, previous research has focused on identifying age-related differences in locomotor performance [7]. Many performance balance measures, such as the timed-up-and go (TUG) [8], one-leg stand (OLS) [9], functional reach (FR) [10], and Tinetti balance [11] tests, are available for evaluating the risk of falling among community-dwelling older people. However, a useful predictor of falls, i.e., the golden standard, does not yet exist.

Nevitt et al. [12] reported that the rate of falling indoors is high. Moving in an indoor environment requires that the individual be cautious and pay attention to various objects, 
particularly when there are two or more obstacles. More recent studies have reported that a decrease in physical function during complex-task conditions is a factor related to falling in elderly individuals [13, 14]. Multitasking or engaging in two or more activities at the same time is common in daily living, and real-life situations are performed in a complex-task environment. The complex-task condition is present when self-induced falls occur during walking, rising from a chair, or stumbling on a rug or inappropriately placed furniture or telephone cord-situations that may occur in daily life [7]. The majority of falls in the elderly occur during common daily activities, such as walking or changing position [1] or from tripping or tangling of the feet. Recent evidence suggests that an impaired ability to allocate attention to balance during complex-task situations is a powerful predictor of fall [8]. It is necessary to distribute suitable attention to complex-tasks simultaneously in a complex-task environment, and this attention function decreases with aging [15].

However, not all reports show that the results of falling are due to a decrease in motor function under a complextask condition [13, 14, 16-18]. Recent reviews have also reported that there is no clear basis for using the intervention under dual-task condition method for preventing a fall [19]. Negative findings on a neuropsychological function test may be caused by an inappropriate task design. For example, when combining a motor and cognitive task, if the difficulty of a cognitive task is very high or very low, the attention given to the cognitive task may not be appropriately distributed. In such a case, even if the assessment includes a dual-task situation, the distribution of attention to the motor task may be equivalent to the attention in a single-task condition. In addition, even if motor performance is part of a dual-task situation, attention to the motor task may not decrease. Moreover, even if maximum effort is devoted to a cognitive task, it is still possible to execute a motor task, such as walking [20].

However, tasks imposed in real life may need to be finished completely. For example, when the task "please stop" is given, it is necessary to "stop" completely. In contrast, completion to perfection is not required for a cognitive or dual task that includes walking. Alexander et al. [21] reported the development of this ambulatory version of the trail-marking test (TMT), but this ambulatory version has a low level of difficulty for community-dwelling older adults. We therefore designed the trail-walking test (TWT) as an improved version of the ambulatory version of the TMT [22]. The TWT consists of walking from numbered flags in ascending or descending order. A cognitive function (visual search function, short-term memory, etc.) and motor function (locomotion, turning, etc.) are simultaneously required to successfully execute the TWT.
The purpose of this study was to evaluate whether TWT would be useful for predicting falls in community-dwelling elderly individuals.

\section{Methods}

\section{Participants}

Participants were recruited by means of an advertisement in the local press. An initial interview screened potential participants based on the following criteria: aged $\geq 65$ years, community-dwelling, having visited a primary care physician within the previous 3 years, a sum score on the Mini-Mental State Examination (MMSE) [23] of $\geq 24$, independent ambulators (use of a cane allowed), willingness to participate in group exercise classes for at least 6 months, access to transportation, minimal hearing and vision impairments, and no regular exercise in the previous 12 months.

The exclusion criteria, which were checked during the interview were severe cardiac, pulmonary or musculoskeletal disorders, pathologies associated with increased risk of falls (i.e., Parkinson's disease or stroke), osteoporosis, and the use of psychotropic drugs. Written informed consent was obtained from each of the 171 communitydwelling elderly individuals (mean age $80.5 \pm 5.6$ years) who were included in the trial in accordance with the guidelines approved by the Kyoto University Graduate School of Medicine and the Declaration of Human Rights, Helsinki, 1975.

\section{Cognitive status measures}

Executive function was assessed using the TMT, a wellestablished psychomotor test originally developed as part of the Army Individual Test Battery [22]. TMT has been widely used in clinical evaluations to assess deficits in executive cognitive function. Part A of TMT is a visualscanning task; the participant is required to draw lines sequentially connecting consecutively numbered circles (No. 1-25) randomly arranged on a page as quickly as possible.

\section{Trail-walking test}

In the TWT environment, flags are installed randomly at each of the 15 positions in a $25-\mathrm{m}^{2}$ area $(5 \times 5 \mathrm{~m})$. The positions at which the flags were placed are shown in Fig. 1. The participants were asked to sequentially move from flag no. 1 to no. 15 (Fig. 1). A 30-cm diameter circle was drawn around each flag. Passage was considered to be successful when the participant stepped on the circle. 
(a)

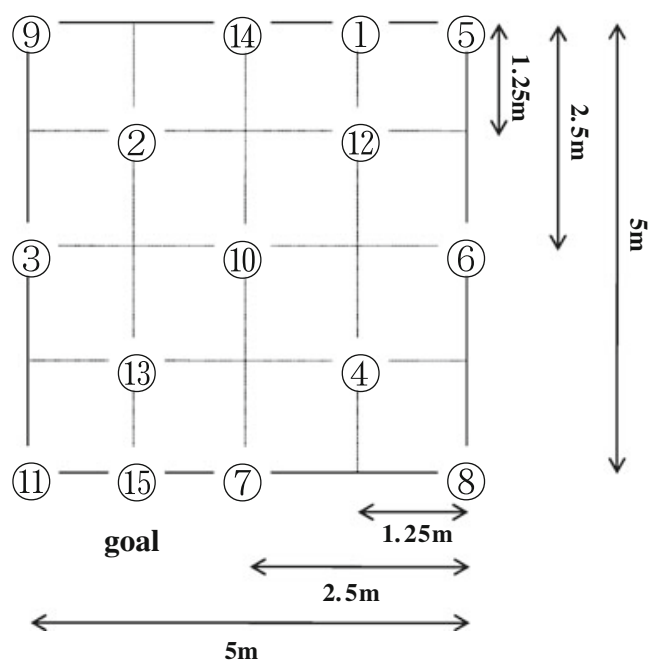

Fig. 1 Schematic of trail-walking test (TWT). a Participants were asked to sequentially move from flag no. 1 to 15 . The tester ordered "Please move to no. 15 as quickly and correctly as possible."

The height of the flag was $30 \mathrm{~cm}$. The tester ordered "Please move to no. 15 as quickly and correctly as possible." The trials were timed using a stopwatch to the nearest $0.01 \mathrm{~s}$ following a standard procedure. The TWT was performed only once. Test-retest reliability was assessed by repeating the TWT within 2 weeks of the first trial at which time the positions of the flags were the same as those in the first trial.

\section{Physical performance measures}

Physical functions were assessed using the TUG [6], FR [24], OLS, and $10-\mathrm{m}$ walking time (10 $\mathrm{m}$ walking) tests [25].

All test measures were completed prior to randomization. Before commencing the study, all staff members received training in the correct protocols for administering all assessment measures included in the study from the author (M. Y.). If a walking aid was normally used at home, then this aid was used during the TUG and 10-m walking.

In the TUG, participants were asked to stand up from a standard chair with a seat height of $40 \mathrm{~cm}$, walk a distance of $3 \mathrm{~m}$ at a normal pace, turn, walk back to the chair, and sit down. The time recorded in the two trials was averaged to obtain the TUG score.

In the FR, each participant was positioned next to a wall with one arm raised at $90^{\circ}$ and fingers extended. A yardstick was mounted on the wall at shoulder height. The distance that a participant could reach while extending

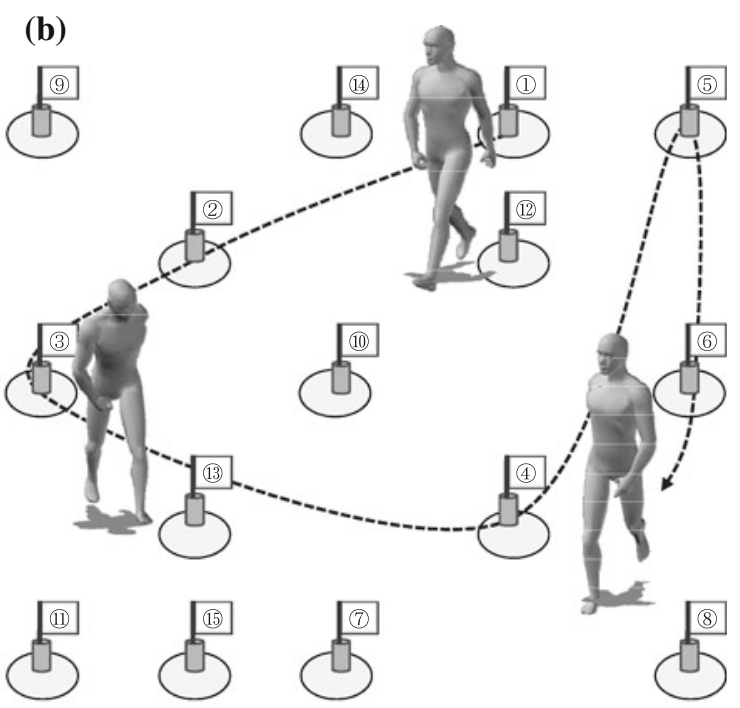

The trials were timed using a stopwatch to the nearest $0.01 \mathrm{~s}$ following a standard procedure. b Schematic of task excursion

forward from an initial upright posture to the maximal anterior leaning posture without moving or lifting the feet was visually measured in centimeters as the third finger tip position against the mounted yardstick. The distances measured in the two trials were averaged to obtain the FR score.

In the OLS, participants were instructed to start from a position with a comfortable base as support, with eyes open and arms along the side of the trunk. They were then instructed to stand unassisted on any one leg. The OLS was tested in seconds from the time one foot was lifted from the floor to when it touched the ground or the standing leg.

In the standardized (ST) walking test, participants were asked to walk $15 \mathrm{~m}$ at a speed that was comfortable to them, and the time to complete the $10-\mathrm{m}$ distance during this walk was recorded using a stopwatch. The time recorded in the two trials was averaged as the ST walking score.

\section{One-year follow-up}

Information on incident falls during the year up to the 1-year follow-up was collected monthly by telephone. A fall was defined as an event that resulted in a person unintentionally coming to rest on the ground, floor, or other lower level with or without loss of consciousness or injury [26]. Falls resulting from extraordinary environmental factors (e.g., traffic accidents and falls while riding a bicycle) were excluded. Falls were recorded in fall diaries that participants were asked to mail to the research 
assistants each month. All participants who had fallen were interviewed during these calls using a structured questionnaire about the fall event and its consequences.

Statistical analysis

Test-retest reliability was assessed by the intraclass correlation coefficient (ICC 1.1) between TWT at the test and retest 2 weeks later, using an analysis of variance.

The relationship between TWT and cognitive and physical performance was investigated with the Pearson correlation coefficient. The $t$ test was used to compare the results of TWT, TMT, TUG, FR, OLS, and the 10-m walking tests between fall and non-fall groups.

Stepwise logistic regression analysis was used to analyze whether TWT, TMT, TUG, FR, OLS, or the 10-m walking tests predicted falling.

Data were recorded and analyzed using the Statistical Package for Social Science (Windows ver. 11.0) (SPSS, Chicago, IL). A $p$ value $<0.05$ was considered to be statistically significant for the analyses.

\section{Results}

Test-retest reliability

The test-retest reliability of TWT was high [ICC 0.945; 95\% confidence interval (CI) $0.95-0.99 ; p<0.001]$.

\section{Correlation analysis}

Table 1 shows the Pearson correlation coefficients between TWT, TMT, TUG, FR, OLS, and the 10-m walking tests that were evaluated a predictors of falling. TWT was correlated with TMT $(r=0.562, p<0.001)$ and TUG $(r=0.243$,

Table 1 Correlation between TWT, TMT, OLS, FR, TUG, or 10-m walking tests

\begin{tabular}{lccrccc}
\hline Measures & TWT & TMT & OLS & FR & TUG & $\begin{array}{c}10-\mathrm{m} \\
\text { walking }\end{array}$ \\
\hline TWT & \multirow{2}{*}{1.00} & $0.56^{* *}$ & 0.06 & -0.09 & $0.24^{* *}$ & 0.08 \\
TMT & & 1.00 & -0.10 & -0.11 & $0.06^{* *}$ & -0.03 \\
OLS & & & 1.00 & -0.09 & -0.09 & 0.11 \\
FR & & & & 1.00 & $0.17^{*}$ & $-0.15^{*}$ \\
TUG & & & & & 1.00 & $0.76^{* *}$ \\
10-m walking & & & & & & 1.00 \\
\hline
\end{tabular}

$T W T$ trail-walking test, TMT trail-making test part-A, $O L S$ one-leg standing test, FR functional reach, TUG timed-up-and-go test, $10-\mathrm{m}$ walking $10-\mathrm{m}$ walking time

* Correlation significant at $p<0.05$; ** Correlation significant at $p<0.01$ $p=0.001)$. The relationship between TWT and OLS, FR, or 10-m walking tests was not significant (Table 1).

Predictive analysis

Fifty-nine participants $(34.5 \%)$ had reported a fall during the year preceding the 1-year follow-up (Table 2). There was no significant difference between groups for age, height, weight, body mass index (BMI), gender, MMSE, independent activities of daily living (ADL), walking aids, and medication $(p>0.05)$. Individuals in the fall group had significantly higher mean values for the TWT $(p<0.001)$, TMT $(p<0.001)$, and TUG $(p=0.003)$ tests compared with those in the non-fall group. There was no significant difference between the two groups for other measures (Table 2).

The stepwise regression model identified the TWT as being the only measure significantly related to falls (odds

Table 2 Characteristics and physical performance between fallers and non-fallers among the study cohort

\begin{tabular}{|c|c|c|c|}
\hline Characteristic & $\begin{array}{l}\text { Faller } \\
(n=59)\end{array}$ & $\begin{array}{l}\text { Non-faller } \\
(n=112)\end{array}$ & $p$ value \\
\hline Age (years) & $79.5(6.2)$ & $81.4(4.9)$ & 0.334 \\
\hline \multicolumn{4}{|c|}{ Age distribution (years) } \\
\hline $70-74(n)$ & $10(16.9 \%)$ & $21(18.8 \%)$ & \\
\hline $75-79(n)$ & $15(25.4 \%)$ & $20(17.9 \%)$ & \\
\hline $80-84(n)$ & $20(33.9 \%)$ & $27(24.1 \%)$ & \\
\hline $85-89(n)$ & $14(23.7 \%)$ & $44(39.3 \%)$ & \\
\hline Height $(\mathrm{cm})$ & $147.1(7.1)$ & $147.1(6.9)$ & 0.982 \\
\hline Weight (kg) & $52.1(10.2)$ & $50.3(7.1)$ & 0.972 \\
\hline BMI & $23.5(3.4)$ & $24.0(3.9)$ & 0.426 \\
\hline Women $(n)$ & $40(67.8 \%)$ & $94(83.9 \%)$ & 0.581 \\
\hline MMSE (point) & $27.9(2.3)$ & $28.1(2.0)$ & 0.762 \\
\hline Independent ADL & $59(100 \%)$ & $112(100 \%)$ & \\
\hline Walking aids $(n)$ & $5(8.5 \%)$ & $13(11.6 \%)$ & 0.609 \\
\hline Medication $(n)$ & $2.7(2.2)$ & $2.9(2.3)$ & 0.777 \\
\hline TWT (s) & $78.2(8.2)$ & $61.5(11.9)$ & $<0.001$ \\
\hline TMT (s) & $91.0(33.7)$ & $66.1(37.6)$ & $<0.001$ \\
\hline OLS (s) & $6.3(5.5)$ & $5.5(5.4)$ & 0.335 \\
\hline $\mathrm{FR}(\mathrm{cm})$ & $24.5(5.7)$ & $24.4(5.7)$ & 0.987 \\
\hline TUG (s) & $13.1(2.1)$ & $12.0(2.7)$ & 0.003 \\
\hline 10-m walking (s) & $11.7(2.8)$ & $11.2(2.6)$ & 0.260 \\
\hline
\end{tabular}

Values are given as the average with the standard deviation (SD) in parenthesis, or as the number with the percentage in parenthesis, where appropriate

$B M I$ body mass index, MMSE mini mental state examination, Independent $A D L$ independent activities of daily living, $T W T$ trail-walking test, $T M T$ trail-making test part-A, $O L S$ one leg standing, $F R$ functional reach, TUG timed up and go test, $10 \mathrm{~m}$ walking $10 \mathrm{~m}$ walking time 
ratio $1.160,95 \%$ CI $1.107-1.214 ; p<0.001)$. Using TWT as a predictor of falls, the regression model was able to correctly classify $77.8 \%$ of the cases $\left(R^{2}=0.488\right.$, $p<0.001$ ). The specificity was $83.9 \%$ and sensitivity was $66.1 \%$.

\section{Discussion}

The results of this study show that approximately $35 \%$ of the community-dwelling adults aged $\geq 65$ years who comprised our study cohort fell at least once during a 1 -year period. This falling rate was consistent with that reported previously $[2,27]$. Our results also indicate that TWT appears to be a reliable measurement because the ICC of the TWT was high. The test results of the TWT were moderately correlated with those of the TMT and TUG tests. We therefore suggest that TWT may be considered a measurement that is related to dynamic balancing ability and attention.

Podsiadlo et al. [8] reported that TUG is useful for evaluating the risk of falling, and a number of studies have linked cognitive impairment and falls or fall-related injuries [2, 5, 28]. The paper-and-pencil TMT evaluates visual scanning and mental flexibility and is also used a predictor of major fall injuries [29]. Previous studies has shown that elderly individuals living in the community with a history of falling have significantly slower TMT times than elderly non-fallers [30]. Based on these reports, we would expect that the TWT may be able to predict the risk of falling in the elderly. We noted that those participants in our study who had a fall during the year preceding the 10year follow-up period required an extended time period to perform the TWT, indicating that the TWT was a predictor for falling. The TWT requires that the subject perform a movement while distributing attention to a number. Not only must attention be focused on a flag, but it is also necessary to use short-term memory for the flag position to reach the next target. In addition, fundamental motor functions, such as locomotion and turning, are needed to perform the TWT. This combination of central nervous system and motor functions is indispensable for activities carried out in everyday life. Consequently, if the ability to execute multiple functions decreases, the risk of falling increases. A number of researchers have reported that the TUG $[8,31]$ and FR tests [10] are useful for assessing fall risk. However, in the elderly, various functions, including motor, cognitive, visual performance, and hearing functions, may be decreasing in a complex manner. In our study, the TWT was most closely correlated to falls in the logistic regression analysis, and TUG and FR were not extracted as significant relevant factors. Therefore, when the aim is to predict falls, we suggest that it is more useful to use multiple-function assessments, such as TWT. Moreover, the result of the TWT is obtained by a simple time measurement, and even if it is assessed by an individual without professional expertise, the measurement is easily made. These considerations suggest the possibility that TWT shows high generality as a risk assessment for falls.

There are several potential limitations to our study and, therefore, interpretation of the results. Firstly, the sample size was small. Secondly, the participants were probably more motivated and showed greater interest in health issues and the risk of falls than the general population of older adults. Thirdly, the TWT was analyzed by repeated attempts. An important point was that a group of pre-frail elderly individuals participated in this study because it was considered necessary to clarify the risks of falling in this group. Therefore, it was meaningful to have predicted the risk of falls in the pre-frail elderly individuals using TWT. Future research should include a fall prevention interventional study. Performance under complex-task conditions may be improved by training with TWT, and this type of training may be helpful for preventing falls.

\section{Conclusion}

This study assessed the usefulness of the TWT, an assessment we devised that is related to the TUG and TMT tests. Based on our results, we suggest that the TWT may be useful for predicting the risk of falling among the elderly.

Acknowledgments The authors acknowledge Dr. Toshiro Sakata and Mr. Toshiaki Uehara for their major contribution to the data collection.

\section{References}

1. Tinetti ME, Speechley M. Prevention of falls among the elderly. N Engl J Med. 1989;320:1055-9.

2. Tinetti ME, Speechley M, Ginter SF. Risk factors for falls among elderly persons living in the community. $\mathrm{N}$ Engl $\mathrm{J}$ Med. 1988;319:1701-7.

3. Scuffham P, Chaplin S, Legood R. Incidence and costs of unintentional falls in older people in the United Kingdom. J Epidemiol Community Health. 2003;57:740-4.

4. Menz HB, Lord SR, Fitzpatrick RC. Age-related differences in walking stability. Age Ageing. 2003;32:137-42.

5. Tinetti ME, Doucette J, Claus E, Marottoli R. Risk factors for serious injury during falls by older persons in the community. J Am Geriatr Soc. 1995;43:1214-21.

6. St George RJ, Fitzpatrick RC, Rogers MW, Lord SR. Choice stepping response and transfer times: effects of age, fall risk, and secondary tasks. Gerontol A Biol Sci Med Sci. 2007;62:537-42.

7. Chen HC, Schultz AB, Ashton-Miller JA, Giordani B, Alexander NB, Guire KE. Stepping over obstacles: dividing attention impairs performance of old more than young adults. J Gerontol A Biol Sci Med Sci. 1996;51:M116-22. 
8. Podsiadlo D, Richardson S. The timed "Up \& Go": a test of basic functional mobility for frail elderly persons. J Am Geriatr Soc. 1991;39:142-8.

9. Vellas BJ, Wayne SJ, Romero L, Baumgarther RN, Rubenstein LZ, Garry PJ. One-leg balance is an important predictor of injurious fall in older persons. J Am Geriatr Soc. 1997;45:735-8.

10. Duncan PW, Studenski S, Chandler J, Prescott B. Functional reach: a new clinical measure of balance. J Gerontol. 1990;45:M192-7.

11. Tinetti ME. Performance-oriented assessment of mobility problems in elderly patients. J Am Geriatr Soc. 1986;34:119-26.

12. Nevitt MC, Cummings SR, Hudes ES. Risk factors for recurrent nonsyncopal falls. JAMA. 1989;261:2663-8.

13. Beauchet O, Dubost V, Allali G, Gonthier R, Hermann FR, Kressig RW. 'Faster counting while walking' as a predictor of falls in older adults. Age Ageing. 2007;36:418-23.

14. Faulkner KA, Redfern MS, Cauley JA, Landsittel DP, Studenski SA, Rosano C, et al. Multitasking: association between poorer performance and a history of recurrent falls. J Am Geriatr Soc. 2007;55:570-6.

15. Baddeley AD. Working memory. Science. 1992;255:556-9.

16. Lundin-Olsson L, Nyberg L, Gustafson Y. "Stops walking when talking" as a predictor of falls in elderly people. Lancet. 1997;349:617.

17. Beauchet O, Allali G, Annweiler C, Berrut G, Maarouf N, Herrmann FR, et al. Does change in gait while counting backward predict the occurrence of a first fall in older adults? Gerontology. 2008;54:217-23.

18. Bootsma-van der Wiel A, Gussekloo J, de Craen AJ, van Exel E, Bloem BR, Westendorp RG. Walking and talking as predictors of falls in the general population: the Leiden 85-Plus Study. J Am Geriatr Soc. 2003;51:1466-71.

19. Zilstra A, Ufkes T, Skelton DA, Lundin-Olsson L, Zilstra W. Do dual tasks have an added value over single tasks for balance assessment in fall prevention programs? A mini-review. Gerontology. 2008;54:40-9.

20. Bloem BR, Valkenburg VV, Slabbekoorn M, Willemsen MD. The multiple tasks test: development and normal strategies. Gait Posture. 2001;14:191-202.
21. Alexander NB, Ashton-Miller JA, Giordani B, Guire K, Schultz $\mathrm{AB}$. Age differences in timed accurate stepping with increasing cognitive and visual demand: a walking trail making test. J Gerontol A Biol Sci Med Sci. 2005;60:1558-62.

22. War Department Adjutant General's Office. Army individual test battery. Manual of directions and scoring. Washington, DC: War Department, Adjutant General's Office; 1944.

23. Folstein MF, Folstein SE, McHugh PR. "Mini-mental state". A practical method for grading the cognitive state of patients for the clinician. J Psychiatr Res. 1975;12:189-98.

24. Duncan PW, Studenski S, Chandler J, Prescott B. Functional reach: predictive validity in a sample of elderly male veterans. J Gerontol. 1992;47:M93-8.

25. Lopopolo RB, Greco M, Sullivan D, Craik RL, Mangione KK. Effect of therapeutic exercise on gait speed in communitydwelling elderly people: a meta-analysis. Phys Ther. 2006;86: $520-40$.

26. Koski K, Luukinen H, Laippala P, Kivela SL. Physiological factors and medications as predictors of injurious falls by elderly people: a prospective population-based study. Age Ageing. 1996;25:29-38.

27. Blake AJ, Morgan K, Bendall MJ, Dallosso H, Ebrahim SB, Arie TH, Fentem PH, Bassey EJ. Falls by elderly people at home: prevalence and associated factors. Age Ageing. 1988;17:365-72.

28. Tinetti ME, Doucette JT, Claus EB. The contribution of predisposing and situational risk factors to serious fall injuries. J Am Geriatr Soc. 1995;43:1207-13.

29. Nevitt MC, Cummings SR, Hudes ES. Risk factors for injurious falls: a prospective study. J Gerontol. 1991;46:M164-70.

30. Lord SR, Fitzpatrick RC. Choice stepping reaction time: a composite measure of falls risk in older people. J Gerontol A Biol Sci Med Sci. 2001;56:M627-32.

31. Shumway-Cook A, Brauer S, Woollacott M. Predicting the probability for falls in community-dwelling older adults using the Timed Up \& Go Test. Phys Ther. 2000;80:896-903. 